\title{
An Empirical Study on the Projection of Specificity in the Usage of Modifiers in Chinese College EFL Writing
}

\author{
Wei Ningling ${ }^{1}$ \\ ${ }^{1}$ School of Foreign Language, LeShan Normal University, Sichuan Province, China \\ Correspondence: Wei Ningling, Leshan Normal University, Binhe Road \#778, Shizhong District, Leshan, \\ Sichuan Province, China. Tel: 18190831733. E-mail: 346289355@qq.com
}

Received: September 26, 2015

Accepted: October 19, 2015 Online Published: October 20, 2015

doi:10.5539/elt.v8n11p207

URL: http://dx.doi.org/10.5539/elt.v8n11p207

\begin{abstract}
Specificity, as a dimension of cognitive construal, refers to the capacity of a speaker to describe an entity or a situation in different accuracy and details (Langacker, 2008), which is linguistically reflected in lexical and grammatical levels (Wen, 2012). Modifiers can extend a simple sentence into a long and complicated one (Weng, 2007), indicating how accurately and substantially an entity or a situation is depicted by a writer. Cognitive linguistics holds the concept that thoughts can be reflected in language (Zhang, 2007) and accordingly the choice of lexical terms and grammatical structures can project the writers' intention and preference (Wen, 2012). Given the projective significance of grammatical structures, the study on the usage of modifiers in EFL writings can demonstrate the projection of specificity and investigate the writers' cognitive activity during writing. Although numerous studies about EFL wring have been done from the perspective of cognitive linguistics in the past decades, research aiming at the cognitive process during writing has been far from satisfaction. Hence, this study will analyze the usage of modifiers and how it projects specificity in specific writing. 20 writing papers are randomly selected as samples written by the second-year college EFL Learners from Leshan Normal University, Leshan, China. Data about the usage of modifiers in each sample are collected by dividing each sentence into smaller unit of modifiers centering on nouns and verbs, ensuring the specificity of each sample to be analyzed in a quantitative level. The study concludes that the writers are inclined to apply modifiers for specificity to a certain extent but the lack of modifier diversity and the partial choice of familiar modifiers indicate monotonous descriptions and personal preference to project certain aspects of an entity or a situation.
\end{abstract}

Keywords: EFL writing, specificity, modifiers, projection

\section{Introduction}

EFL writing (English as Foreign Language writing) is one of the communicative means for EFL learners to master. As for Chinese college EFL learners the task of writing appears in most English tests like CET-4 (College English Test-level 4) or CET-6 (College English Test-level 6), requiring them to express their opinions accurately and fluently (Cai, 2002). Indeed EFL writers differ in accuracy of their writing, exposing varying capabilities to conceive an entity or situation in detail, or specificity of a cognitive construal dimension, linguistically reflected in lexical and grammatical levels. As for Chinese EFL writing, few studies (Wen, 2012) have been conducted on specificity in lexical level, demonstrating the feasibility of improving EFL learners' ability for accurate description by lexical selection. However, the study in grammatical level still needs further supplement. Modifiers are applied as a feasible measure to extend a sentence (Weng, 2007), making an entity or situation being described in a more accurate and substantial manner for specificity. Hence, investigating to what extent EFL writers tend to describe an entity or situation by applying modifiers and to which aspects their focuses are preferentially directed mean a lot for the analysis of projection of specificity and for inspiration to advance their writing performance in the future.

\section{Literature Review}

In China numerous studies have been conducted to investigate EFL writing and have contributed prominently to the improvement of Chinese EFL learners' writing performance, which are mainly devoted to three aspects 
(Zhan \& $\mathrm{Ai}, 2015)$ : the teaching and learning of EFL writing, the factors affecting EFL writing and the analysis of EFL writing samples.

The teaching of EFL writing in China is primarily grounded on two theoretical bases (Luo \& Li, 2003): product approach and process approach. Product approach features bottom-up syntactical structures, highlighting learners' ability to construct sentences and teachers' emphasis of grammar teaching (Ren \& Nuan, 2008). But some researchers (Jia, 1998; Li, 2000) claim that product approach is not compatible with current EFL learning, being proved not effective in both teaching and writing (Cai, 2002; Zhang, 1993; Li, 2000). Thus, they advocates to adopt process approach which has been wildly applied in western countries for a long time (Raimes, 1983; Zamel, 1985; Hedge, 1988; White \& Arndt, 1991). It emphases cooperation among learners and their writing process, which should be consisted by three steps: pre-writing, drafting and revision (Luo \& Li, 2003).

EFL writing has been reported to be affected by various factors, among which metacognition is most studied. Metacognition includes knowledge about when and how to use particular strategies for learning or for problem solving (Metcalfe \& Shimamura, 1994). The studies of metacognitive theories in English writing have been conducted as early as 1990s (Devine et al., 1993; Devine, 1993; Kasper, 1997; O'Malley \& Chamot, 1990; Victori, 1999), whereas in China interest in it is merely aroused in recent years. Tang fang and Xu Jingfen (2005) do a comprehensive literature review of the studies done from the a metacognitive perspective both in China and abroad, illustrating an overall picture of research tendency; Wu Yunshu (2008) compares the differences in the metacognitive knowledge of successful and unsuccessful writers in an empirical study, urging EFL teachers to take students' diversity into consideration; Han song (2008), who conducts a statistical analysis of the questionnaires to find out the metacognitive features of the EFL writing, proving that there is a positive relation between metaknowledge and their writing achievements; Ruan Zhoulin (2011) proposes an interactional model of metacognitive knowledge, which is capable of explaining aspects of knowledge and cognitive activities in the process of Chinese students' English writing. Liu Wenyu and Gao Wentao (2011) certify that meta-cognitive training has a positive effect on English writing. Other factors have also been brought into attention. Zhang Qi (2014) analyzes several cognitive problems and proposes the solutions. Tang Zhiming and Guo Zhengliang (2015) proves that four sub-processes such as generating ideas, translating ideas, linguistic monitoring and discourse monitoring have a close relation with EFL writers' performance. All these studies acknowledge the possibility of studying the intangible cognitive process during writing and prove the verification of improving writing performance by monitoring metacognition or cognitive activities. Although these findings can guide writer to construct a discourse before writing, self-monitor during writing and feedback after writing, it is done on a macroscopic scale failing to narrow down the scope to sentences, grammatical structures or even single words.

The analysis of writing samples features empirical researches, being based primarily on three points (Wang, 2005): 1) the role of native language played in EFL writing; Guo Chunjie and Liu Fang (1997) takes both quantitative and qualitative researches to analyze the influence of native language in EFL learners' writing, discovering that the more native language is involved, the more poorly their writing is performed. The negative correlation between the involvement of native language and writing performance is further proved in Wang Wenyu and Wen Qiufang (2002); 2) the characteristics of EFL writing in lexical, syntactical and discourse levels. $\mathrm{Xu}$ Yuchen (2002) proves the usage of word repletion, synonyms and antonyms is closely related with writing achievements. Zeng Xiangmin. (2011) analyzes the past tense in EFL writing samples and concludes that discourse structure can affect the usage of past tense; 3) the factors affecting EFL writing. Wu Hongyun and Liu Runqing (2004) discover that the metacognitive capability is affected by metacognitive strategies and meta-evaluation ability. These studies prove the practical significance of empirical research. All these studies demonstrate the feasibility to analyze writing problems in quantitative and qualitative levels.

Thus, this study will feature empirical study and analyze specific writing samples on a quantitative scale to clarify how the usage of specific grammatical structures (modifiers) project cognitive construal (specificity), illustrating the significance of writers' intention and preference on linguistic arrangements. This article also values the study of process, which is highly advocated in the method of procedure dominating in western wiring theory (Ren \& Luan, 2008).

\section{Theoretical Basis}

\subsection{Specificity of Cognitive Construal}

Cognitive linguistics states that a situation can be perceived in different ways, which is referred as cognitive 
construal. Langacker (1991) gives an accurate definition: "construal is our ability to conceive and portray the same situation in alternate ways." It includes three main dimensions: specificity, prominence and perspective.

Specificity (Langacker, 2008) refers to the capability that speakers describe the same situation in different accuracy and details. It accounts for the phenomenon that some writings are more vivid and accurate than others (Wen, 2012). Langacker (2008) states that "we have the capacity to conceive an entity or situation at varying levels of specificity and detail as witnessed by such hierarchies as thing $>$ creature $>$ insect $>$ fly $>$ fruit fly. Each term in the hierarchy is schematic for (and elaborated by) the one that follows, which characterizes the designated entity with greater precision (finer resolution)", indicating that specificity can be manifested in lexical level (Wen, 2012). This view is further illustrated in the example of "substance $<$ liquid $<$ beverage $<$ wine $<$ Chianti", in which the hierarchy of specificity of a liquor is increasing in lexical level. In the example of "sprint $>$ run $>$ move $>$ act $>$ do", the hierarchy of specificity of an action is decreasing. Specificity can also be demonstrated in grammatical level (Wen, 2012), in which modifiers can especially extend a sentence into a more complex one (Wen, 2007), enriching the details of the expression. For instance, "the gold-lined Lily in the sunshine", in which the non-finite verb "gold-lined" acting as attribute gives a detailed description of Lily's color and the prepositional phrase "in the sunshine" introduces the location of the flower. The two modifiers leave us an impression of a golden lily bathing in golden sunshine. In the example of "excessively- packaged moon cakes are sold all around Chinese markets, causing a serious waste of recourses", the modifier of non-finite verb as attribute, "excessively-packaged", is used to describe the cakes' luxurious packaging and the modifier of noun, "moon", to depict the cakes' shape. Moreover, the modifier of prepositional phrase "all around Chinese markets" introduces the information of the selling place and an even more complicated non-finite as adverbial modifier "causing a serious waste of recourses" tells the bad effects of this behavior. The former two help to give a more detailed and accurate description of cakes while the latter two elaborate the place of the action of "sell" and the logical relation of cause and effect.

It seems that selecting a specific word (mainly noun or verb) is a feasible way to give an accurate description in lexical level (Wen, 2012). Besides, the more effective way is to describe by applying modifiers, which can extend the expression and enrich the description in a more precise and detailed manner (Wang, 2015). Thus, this article will exclusively highlight how specificity is projected in the usage of various modifiers.

\subsection{Specificity and Modifiers}

English, as a form-dominating language, can be highly condensed into the structure of "subject + predicate". Generally speaking, nouns, infinitives, non-finite verbs and nominal clause can take the place of subject; Predicate is acted by verbs (Zhang, 2009). The highly-condensed structure can be extended into a long and complicated sentence by adding modifiers, which are mainly centered on nouns and verbs for sentence meaning expansion (Wang, 2015). They are categorized by linguists into adjective modifiers and adverbial modifiers with the former being intended to describe nouns (entity) and the latter to verbs (situation) (Weng, 2007). The former is meant to specify nature, shape, color, quality, quantity, location, possessive relation or even complicated logical relations of an entity, while the latter is to time, location, way, motivation, intention, condition, consequence, cause and effect or other logical relations of a situation. According to the grammatical rules (Zhang, 2009), in order to describe a noun in detail, we can attach, as its modifiers, nouns (e.g., country life, labor intensity), adjectives (e.g., artistic effects, a historic relic), possessive pronoun (e.g., my dictionary, your package), prepositional phrases (e.g., the old woman in the room, my grandpa from a village in Shandong), clauses (e.g., the book of which cover is green, the package which you are carrying), infinitives (e.g., the letters to write, someone to help with the work), non-finite verbs (e.g., a sleeping child, the money kept to buy a house) and collocations (e.g., a large amount of, all kinds of). If we intend to describe a verb more accurately, adverbs, prepositional phrases, infinitives, non-finite verbs and adverbial clauses can be selected to complement the verb. For example: "walk as quickly as young people" (adverb); "He went out shutting the door" or "Not knowing what to do, he went to his parents for help" (non-finite verb); "I shut the door quietly, in case that I would wake the baby" or "You can go to the party if you finish your work" (adverbial clause); I come here only to say good-bye to you (infinitive); "he ran for shelter" or "They play football in spite of the rain" (prepositional phrase).

These examples demonstrate that by applying different types of modifiers to describe a noun or a verb, different aspects of an entity or a situation is intended to be specified. The application of adjective or noun to modify a noun can specify its nature or quality, with possessive pronoun for its possessive relationship, prepositional 
phrases for its location or direction, or clauses, infinitives and non-finite verbs for its involvements in different logical relationships; as for the modifiers to a verb, the application of adverb and prepositional phrase is intended to project the specificity of location, direction or purpose of a situation, with non-finite verb, infinitive and adverbial clause for the specificity of time, location, way, motivation, condition, consequences, intention, cause and effect or other logical relations. Then, this study will probe into the usages of modifiers centering on nouns and verbs in EFL writing papers and investigate how they project different aspects of specificity.

\section{Methodology}

\subsection{Research Questions}

In order to investigate how specificity is projected by the usage of modifiers this study is designed to solve the following questions:

1) To what extend are writers inclined to use modifier to describe nouns and verbs for specificity? 2) What types of modifiers do they tend to use? 3) What aspects of specificity does the usage of different types of modifiers project?

\subsection{Subjects}

The participants were 60 second-year non-English majors aging from 19 to 22, who were studying at Leshan Normal University, Leshan, China. They were chosen without considering the gender but with the premise that they all passed CET-4, ensuring the proficiency to be able to express thoughts in an accurate, coherent and grammatically correct way (Cai, 2002).

\subsection{Instruments}

The selected subjects were required to sit in a classroom and finish a topic in 30 minutes without preparing it previously. The proficiency-catering topic of CET-4 in 2012-“On excessive packaging"-was chosen as the writing topic, which was meant to be written as an argumentation. If it is for the rhetorical mode of description, EFL writers are eagerly inclined to describe an object or a situation with more details in a more deliberate manner. Thus, an argumentation can better reflect their normal tendency of utilizing modifiers. The total number of words was restricted not to exceed 150 words, which is enough for a decent and appropriate argumentation according to the requirements of CET-4. 30 minutes later the 60 papers were submitted and after a rough scam the author collected 57 valid samples with complete structures and topic-centering contents, from which 20 samples were randomly selected.

\subsection{Procedures}

This study takes the method of quantitative research. The data collecting include the following two specific steps:

1) Categorization. Modifiers are mainly categorized into adjective modifier and adverbial modifier (Weng Yiming, 2007). Since adjective modifier is related to nouns while adverbial modifier to verbs, with quantification being considered, modifier types are quantified by centering on each noun (object) and each verb (action). Modifiers for nouns (or adjective modifiers) are classified into the following 8 types: infinite as attribute, subordinate clause, adjectival possessive pronoun, collocation, non-finite verb as attribute, prepositional phrase, adjectives and nouns. Modifiers for verbs (or adverbial modifiers) are categorized as adverbs, adverbial clause, prepositional phrase, non-finite verb as adverbial modifier, and infinite as adverbial modifier. With convenience and conciseness being concerned, as for the modifiers of nouns, the subordinate clause includes attributive clause and nominal clause (appositive clause, subject clause and object clause); adjective includes attributive adjective along with the predicative adjective used in copula-predicative structure and the adjective of object complement; possessive pronoun includes adjectival possessive pronoun and demonstrative pronoun; non-finite verb as attribute includes gerund; copula is excluded from verbs.

2) Quantification. As for each sample, the nouns and the verbs are brought into focus first and the total numbers of nouns and verbs are quantified separately. Then, centering on each noun and each verb, the number of various modifier types are quantified. Since the specificity of describing an object or an action can be reflected in the number of modifiers applied to describe each noun or each verb, the more modifiers they utilize for a noun or a verb, the more accurate and substantial the description of an object or event is intended to be. Thus, the proportions of the number of modifiers used for nouns or verbs to the total number of nouns or verbs can explain whether the writer is inclined to apply modifiers for description. Furthermore, the proportion of the number of 
each modifier type used for nouns or verbs to the total number of modifiers in a sample can explain the modifier diversity and personal preference.

\subsection{Data Analysis}

After careful categorization and quantification, four figures are made to explain how modifiers are applied in EFL writing. Figure 1 represents the modifier percentages of nouns, which is acquired by the number of each modifier type dividing the total number of modifiers. Figure 2 represents the same indication with Figure 1 except for verbs but not nouns. These figures can present a clear view about to what extend the writers are inclined to use modifiers to describe nouns or verbs in a more precise manner and how much modifiers they apply; it can also be illustrated which writer is the most frequent modifier user and which one is the least. Figure 3 and Figure 4 are respectively intended to show the numbers of noun-centering and verb-centering modifier types, indicating an overall picture of modifier distribution and personal preference.

1) The tendency to use modifiers.

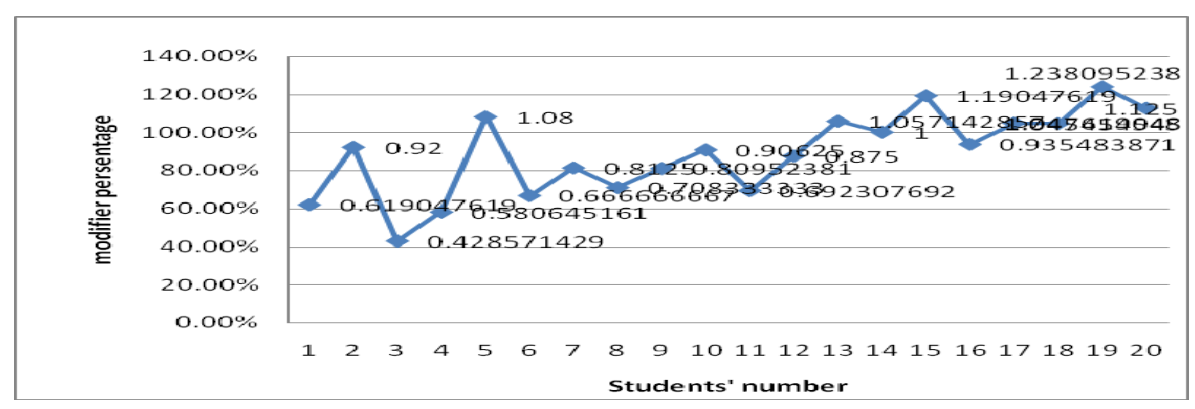

Figure 1. Modifier percentage of nouns

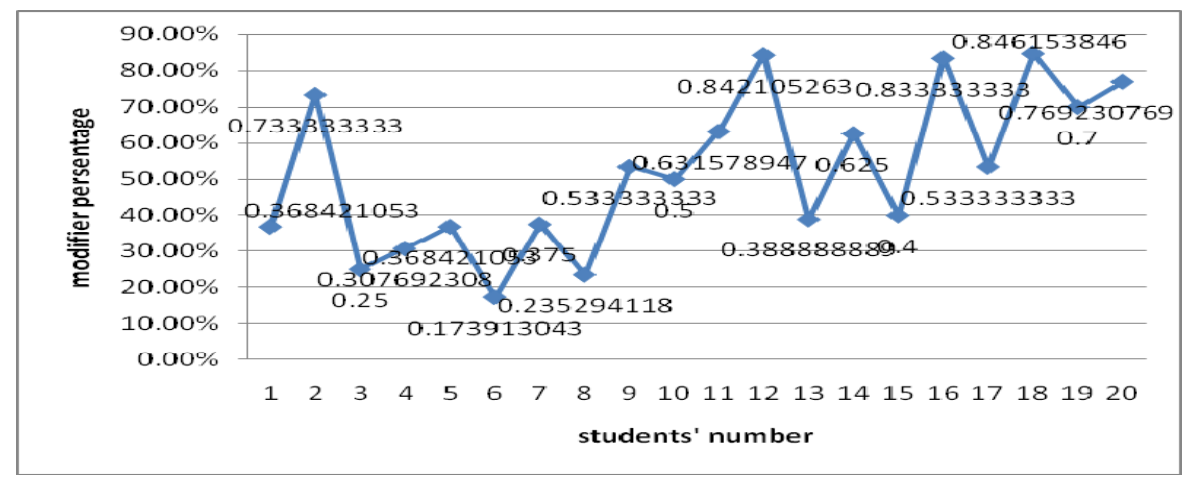

Figure 2. Modifier percentage of verbs

Figure 1 and Figure 2 indicate that all the writers are inclined to use modifiers to describe the nouns and verbs in a more accurate and substantial way for specificity. As data in Figure 1 being demonstrated, all the applications of modifiers for describing nouns exceed $50 \%$ except for the least modifier-user (No. 3) reaching about $40 \%$; the most modifier-user reach $124 \%$, implying that averagely a single noun is modified in more than one ways. The data in Figure 2 indicates that the EFL writers try to attach a modifier to a verb with 11 usages exceeding 50\% but Compared with Figure 1 the application is not as frequent as that to a noun.

2) The diversity and preferences. 


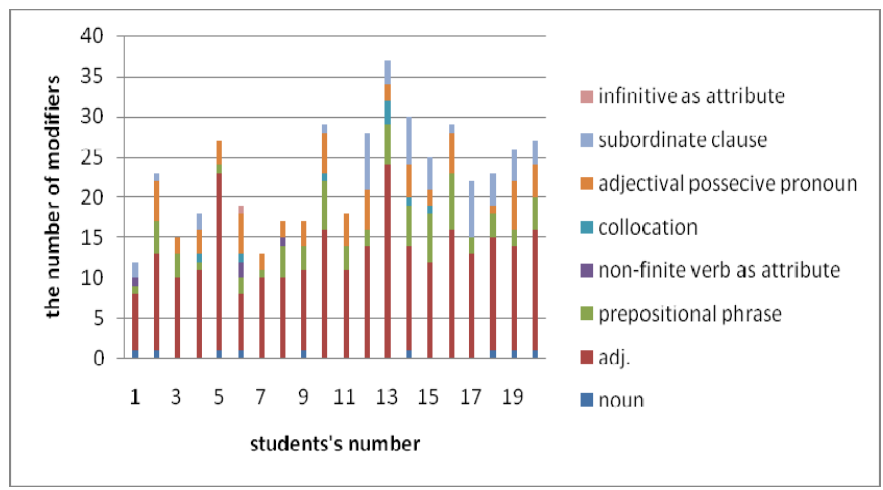

Figure 3. Types of modifiers used to modify nouns

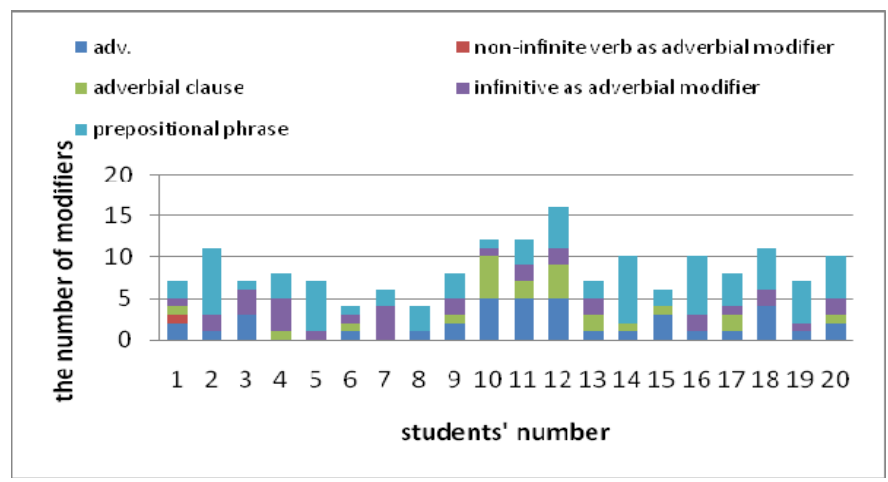

Figure 4. Types of modifiers used to modify verbs

According to the data in Figure 3, adjectives are the most frequently applied modifier for all the writers. In their specific samples, No.13, No.5 and No.10, as the most frequent adjective-users, tend to repeat such general adjectives as "excessive", "beautiful", "good", etc. to describe the noun "packaging" or they use a large number of "many" or "some" to express an ambiguous number of nouns; the students are also inclined to use adjectival possessive pronoun to manifest possessive relations of the nouns. For example, No.19, No.2, No.6, No.10 and No.12 use a lot of "our" and "my" in the expressions like "our life", "our money", "our country" or "my opinion". Their excessive use of the self-centered pronouns indicates their preference to describe or argue from a subjective but not objective view; prepositional phrases are also applied frequently, especially the preposition "of" to illustrate the possessive relations. For instance, the expressions like "the development of our country", "the production of goods", "a waste of resources" and "atmosphere of saving" can be easily found in No.16; in a couple of papers, subordinate clauses can be found, but most of them are object clauses guided by "that". For example, in the sample of No.17 there are a lot of sentences like "they think that they can use packaging sometimes", "I think that we should advice customers not to buy that" and "I hope that here will be less productions...", but only one attributive clause as modifier can be found; collocation is seldom used except for the repeating use of "a lot of", exposing the poor accumulation of collocations; the students unanimously avoid to use infinitive, noun and non-finite verb as modifier to describe nouns, except for the expressions with non-finite verb as noun like "living standards" and "giving others gifts usually is a way to show their..." in the sample of No.6, and with noun as modifier like "shop keeper" and "environment consciousness".

The data in Figure 4 shows that the most popular modifier for verbs is adverb. Such adverbs as "excessively" and "especially" can be easily found in the most frequent user No.2, No.5 and No.12; the use of prepositional phrases is dominated by location-indicating or approach-indicating prepositional phrases, such as "in a ...way" and "by..." or by object-directing ones like "to..." and "for..."; the third most frequently applied modifiers are infinitive mainly to express purpose in the expression "...to buy the beautiful product", and the adverbial clause to indicate the relation of cause and effect of an event like "....because the beautiful product can satisfy their vanity"; the writers are inclined to avoid the use of non-finite verb as modifier except for the expression of "the 
packages are abandoned, causing pollution" in No.1.

\subsection{Results}

The choice of lexical terms and grammatical structures can project the writers' intention and preference (Wen Xu, 2012). The results indicate that: 1 ) during writing the students are inclined to use modifiers to describe nouns and verbs for specificity with the former exceeding the latter in total number, projecting that the writers tend to more frequently specify nouns than verbs. However, the modifiers they select are monotonous and only refrained to the simplest and most direct forms. In the terms of modifying nouns and verbs, the most-welcome modifiers are adjective and adverb, the forms of which are simple and whose meaning and usage are easy to be remembered and applied. This indicates that the writers concern more about the quality, nature, status or characteristics of an entity or a situation. However, their specific expressions in each sample demonstrate the selected adjectives and adverbs are mainly restricted to the general words but not specific subordinate ones and the same words are repeated frequently. The limited word selection exposes the weakness that the writers are short of vocabulary and the learned words in their mind are scattered in disorder but not organized in a systematic way. Thus, when they retrieve words from their memory, the first ones popping out are the most general words and the most specific ones are hidden in the back of their mind; 2) the excessive use of possessive nouns like "my", "our", "your" and "their" projects that when it comes to nouns, the first attention of specificity is given to the possessive relation between the thing and its possessors. The excessively used "my" and "our" make the whole text subjective, which implies that the writers cannot open their mind and extend the vision to a more objective view. Most of the Chinese college EFL learners keep themselves in ivory tower and stay away from the realistic life. They are willing to stay in their own life but not so concerned about the outside world. Thus, they tend to treat a matter from their own view but not on the basis of objective facts; 3 ) the writers tend to avoid the use of non-infinite verbs and infinitive as attribute or adverbial modifier, whose usages are missing in their native language. For example, the students repeat the expression of "excessive package" but seldom try to use the expresses like "excessively-packaged goods" or "the goods packaged in excessive way". This tendency projects that in a short of writing time it is difficult for the writers to clarify the logical relations like cause and effect and transition, making the writing less logically specific and imprecise. Since the logical relations in non-infinite verbs and infinitive are reflected in grammatical structures, their usages are difficult for the learners speaking Chinese, of which logical relations are reflected in meaning and context but not in grammar. It is the ambiguity and ideographic character of Chinese that result in the lack of rigorous logic thinking of Chinese native speakers.

According to the analysis, it can be concluded that the writers are inclined to use modifiers to specify what they intend to but the description is lack of diversity due to the monotonous choice of one or two familiar modifiers. The use of the words with general meanings and the repeating of the same word impair the specificity of the objects and the action. Moreover, the preference to subjective modifiers projects that the writers' tendency to specify an objectivity-requiring writing in subjective perspective. Furthermore, the evading of modifiers of non-finite verbs demonstrates the failure to describe the hidden logical relations between objects and actions, which can cripple the specificity of various relations and reflect.

\section{Discussion}

This study has investigated how the usage of modifiers projects various aspects of specificity in Chinese EFL learners' writings. The results highlight that EFL writers are inclined to apply modifiers while describing a noun or a verb but in a monotonous and partial manner but the lack of modifier diversity and preference to familiar ones expose the poor acquisition of linguistic knowledge and project writers' intention to specify particular aspects of an object or a situation. Henceforth, three inspirations for the teaching of college EFL writing can be suggested: 1) while teaching vocabulary, along with the meaning and usage of words, the teacher should help the students to take the learned words into a systematical network, in which the students can distinguish general words and the subordinate ones, and teach them how to use specific words to describe details; 2) the teaching of vocabulary and grammar should be combined. With the usages of words, the students can only describe in a lexical level. With the usages of various modifiers, the students can only describe in a structural level. Only by combing words and modifiers can writing be made in specific and accurate details; 3 ) along with language teaching, cognitive activity is also important. How to observe in an objective way and how to construct logical relations are two critical problems before writing. The teacher should take the responsibility to enrich the students with objective facts and show them how to think in a logical way.

Nevertheless, there are certain limitations on the findings of this study: 1) the size of the sample was not big 
enough to obtain generalized results. It is hard to say the 20 randomly selected samples can represent all the Chinese college EFL writing problems; 2) the modifiers counted in this study are mainly centered on nouns and verbs. As we know, infinitive, non-finite structure or even the whole sentence can be modified. Thus, the statistics were only collected on the premise of analyzing students' most frequently used sentence structures; 3 ) the statistics were acquired by dividing each sentence into smaller units of modifiers, the usage of which are flexible, and thus there could be deviation in the data

\section{References}

Cai, J. (2002). Influence of CET writing requirements and scoring criteria on Chinese students' compositions. Journal of Pal University of Foreign Languages, 5, 49-53.

Chen, S. (2010). Research on ESL writing process from the perspective of cognitive linguistics. Journal of social science of Hunan Medical University, 4, 98-99.

Devine, J. (1993). The role of meta-cognition in second language reading and writing. In J. G. Carson, \& I. Leki (Eds.), Reading in the Composition Classroom: Second Language Perspectives. Boston: Heinle and Heinle.

Devine, J., Railey, K., \& Boshoff, P. (1993). The implications of cognitive models in L1 and L2 writing. Journal of Second Language Writing, 2, 203-225. http://dx.doi.org/10.1016/1060-3743(93)90019-Y

Guo, C., \& Liu, F. (1997). A dynamic research into L1 influence on L2 writing. Morden Foreign Language, 4, 31-38.

Han, S. (2008). An empirical study of meta-cognition in postgraduates of English majors' writing. Foreign languages and their teaching, 10, 53-56. http://dx.chinadoi.cn/10.3969\%2fj.issn.1004-6038.2008.10.012

Hedge, T. (1988). Writing. Oxford: Oxford University.

Jia, A. (1998). The advance of English writing: from product approach to process approach. Journal of Pla University of Foreign languages, 5, 74-77.

Kasper, L. F. (1997). Assessing the metacognitive growth of ESL student writers. TESL-EJ, 3(1), 1-20

Langacker, R. W. (1991). Foundations of cognitive grammar Vol. II: Descriptive Application. Stanford, California: Stanford University Press.

Langacker, R. W. (2008). Cognitive grammar: a basic introduction. Oxford: Oxford University Press. http://dx.doi.org/10.1093/acprof:oso/9780195331967.001.0001

Li, S. (2000). The critical measures to advance English writing teaching: process approach. Foreign Language World, 1, 19-23.

Liu, W., \& Gao, W. (2011). The study on the influence of meta-cognitive training on English writing. Foreign Language Education, 2, 60-63.

Luo. Y., \& Li, H. (2003). Is product approach really out of date? Journal of Xian International studies university, 6, 22-25.

Metcalfe, J., \& Shimamura, A. P. (1994). Metacognition: knowing about knowing. Cambridge, MA: MIT Press.

O’Malley, J. M., \& Chamot, A. U. (1990). Language learning strategies in second language acquisition. Cambridge: Cambridge University Press. http://dx.doi.org/10.1017/CBO9781139524490

Raimes, A. (1983). Techniques in teaching writing. New York: Oxford University Press.

Ran, Z. (2011). Metacogntive knowledge and critical thinking in L2 writing. Foreign Language in China, 3, 59-64. http://dx.chinadoi.cn/10.3969\%2fj.issn.1672-9382.2011.03.010

Ren, C., \& Luan, S. (2008). Approaches of English writing methods: An analysis. Shangdong Foreign Language Teaching, 5, 78-80.

Tang, F., \& Xu, J. (2005). A literature review of meta-cognition in English writing both in China and abroad. Foreign Language World, 5, 17-22.

Tang, Z., \& Guo, Z. (2015). A research on cognition of EFL writers of non-English Majors. Journal of Fujian Agriculture and Forestry University, 1, 103-108. http://dx.chinadoi.cn/10.13322\%2fj.cnki.fjsk.2015.01.019

Victori, M. (1999). An analysis of writing knowledge in EFL composing: A case study of two effective and two 
less effective writers. System. http://dx.doi.org/10.1016/S0346-251X(99)00049-4

Wang, K. (2015). The study on the usage of modifiers in college English. Journal of Ezhou University, 6, 74-75.

Wang, L. (2005). Empirical studies on L2 writing in China: a review. Foreign language In China, 2, 50-55.

Wang ,W., \& Wen, Q. (2002). The relation between native language and scores of English writing. Foreign Languages and Their Teaching, 10, 17-20.

Wen, X. (2012). Cognitive construal and its implications for FLT: an exploration of applied cognitive linguistics. Contemporary Foreign Language Studies, 2, 5-8.

Weng, Y. (2007). The linguistic phenomenon of ambiguity caused by improper use of modifiers. Journal of Liaoning Technical University (Social Science Edition), 9, 640-542. http://dx.chinadoi.cn/10.3969\%2fj.issn.1008-391X.2007.05.030

Wu, H., \& Liu, R. (2004). The analysis of L2 writing metacogntive. Foreign Language Teaching and Reasearch, 3, 187-196. http://dx.chinadoi.cn/10.3969\%2fj.issn.1000-0429.2004.03.004

White, R., \& Arndt, V. (1991). Process writing. London: Londonman.

$\mathrm{Wu}, \mathrm{Y}$. (2008). A comparison of metacognitive knowledge between successful and unsuccessful EFL writers. Journal of Huainan Normal University, 6, 115-120.

$\mathrm{Xu}, \mathrm{Y}$. (2002). The relation between lexical cohension and the quality of English writing. Foreign Language Teaching Abroad, 2, 33-37.

Zamel, V. (1985). Responding to student writing. TESOL Quarterly, 19(1), 79-101. http://dx.doi.org/10.2307/3586773

Zeng, X. (2011). The influence of lexical aspect upon the simple past variation in the narrative discourse. Journal of Southwest JiaoTong University, 4, 32-37.

Zhan, S., \& Ai, D. (2015). The literature review of English writing for the past 15 years in China. Theory and Practice of Contemporary Education, 2, 118-121.

Zhang, H. (2004). The effect of cognitive linguistics on English writing. Journal of Zhengzhou University, 3, 103-105.

Zhang, L. (1993). The analysis of EFL writing process. Foreign Language World, 4, 15-18.

Zhang, L. (2007). The theoretical basis of cognitive thinking in language and langue-the relation between cognitive thinking and logical thinking. Journal of Capital Normal University, 2, 99-114.

Zhang, Q. (2014). An analysis of cognitive problems in Chinese college students' cross-cultural English writing. Overseas English, 18, 101-102.

Zhang, Z. (2009). The course of English grammars. Shanghai: Shanghai Education Press.

\section{Copyrights}

Copyright for this article is retained by the author(s), with first publication rights granted to the journal.

This is an open-access article distributed under the terms and conditions of the Creative Commons Attribution license (http://creativecommons.org/licenses/by/3.0/). 